The two reactions in the series were not severe, one was easily controlled by intramuscular phenergan and in neither case was there adverse effects to either mother or child.

Having started the drip, the supervision of its progress can be delegated to a DI-AMAH or trained nurse, providing a briefing is given on side effects, etc.

\title{
THE MCGRIGOR MANUSCRIPTS
}

DURING 1963 I found it necessary to visit Great Britain to gather additional material for the biography of Sir Andrew Smith, M.D., K.C.B. While in Scotland, it occurred to me to investigate the history of the Aberdeen Medico-Chirurgical Society, which was founded by Sir James McGrigor in 1789, and which had elected Dr. Smith an honorary member in September, 1855. In doing so, the Society had presented him with an address, the original of which is in my possession.

I was therefore particularly anxious to examine the minute books of the Society, in order to see if Dr. Smith's reply had been preserved, and the honorary secretary, Dr. Clark, generously gave me access to them. In them I discovered a transcript of the important document for which I was seeking, though the original letter had not been preserved.

But while browsing through the excellent library of the Society, I came across a shelf full of manuscript volumes which had belonged to Sir James McGrigor, and which had been donated by him to the Society in 1847 . In one of these I found not only the letter which had accompanied the gift, but also a catalogue of the manuscripts in the collection. The letter, which was addressed to "The President of the Medical Society, Aberdeen ", was dated "London, 4th August, 1847" and had obviously been copied by a clerk, but signed by Sir James.

"Sir,

I send by the Ship (no name given) Volumes of Manuscripts being chiefly Cases of Disease which occurred in the Regimental Hospital of the 88th Regiment and of the Royal Regiment of Horse Guards when I was Surgeon of these Corps and subsequently when I was on the Medical Staff of the Army, and which I beg you to present in my name to the Medical Society of Aberdeen. In presenting these Volumes, I do so not on account of their value which I am very sensible is but small but as holding out to the Society an instance of the persevering Industry with which I prosecuted my profession from my first entrance into the Army and to which I mainly attribute my success in it. The Clinical Cases are generally in my own handwriting, but sometimes in that of my Assistants in the two Regiments in which I served as Surgeon, vizt. nearly 11 years in the 88th Regt. and about two years in the Royal Regiment of Horse Guards. My assistants were 


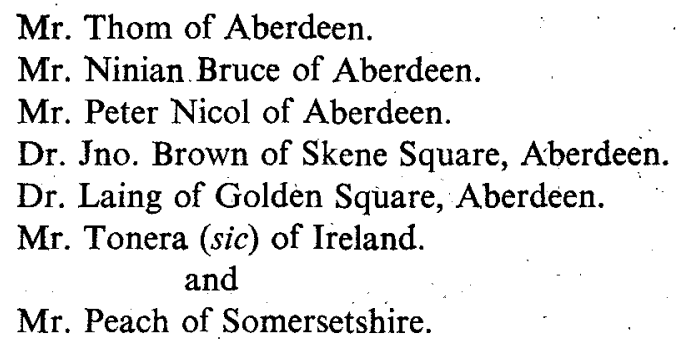

I was, I believe, the Instituter of the Medical Society of Aberdeen, for after my return from Edinburgh, where $I$ had been a Member of the Medical and Chirurgical Society, in a conversation with the late Dr. James Robertson I suggested such an Institution as I had been a Member of in Edinburgh, and in a short time after the Society commenced its Sittings. With my warmest wishes for its prosperity.

\section{I have the honour to be, Sir, \\ Your most obedient servant, J. McGrigor".}

The catalogue is too extensive to reproduce here in its entirety. It consists of eight foolscap pages, written by hand on blue paper with no watermark. Page 1 is headed "Manuscripts belonging to Sir James McGrigor, Bart", and begins with a list of "Case Books ", 1802-1809, largely 88th Regt., and includes Nos. 1, 3, 4, 5, 6, etc. up to 30 (Nos. 2 and 29 are not mentioned). The latter is of the Royal Horse Guards, Blues.

There are also copies of Reports, 1797-1798, a volume of Miscellanies which includes, inter alia, Register of the Weather from 1801-1804. Also further volumes of Miscellanies, about 10 volumes of letters (Letter-Books c. 1809-1815), and, in three foolscap pamphlet cases, " 13 Books unbound containing Journal of Events which occurred to the Army in the Peninsular from Dec. 1811 to June 1813".

Although these manuscripts are naturally treasured by the Aberdeen Society, they are rarely, if ever, consulted, and I cannot help feeling that they would be more appropriately housed at Millbank where they would be not only in the company of the many similar volumes of later date, but also more readily accessible to students of military. medical history.

One of my main objects in coming to Britain, however, was to examine the great collection of Army Medical Reports which had been made by Sir James McGrigor throughout the many years during which he was Director-General of the Army Medical Department. In the "Supplementary Chapter" to McGrigor's "Autobiography" are listed well over three hundred volumes of these Reports, which had been sent to the Director-General from every British military station throughout the world, and then bound, indexed and labelled. A classified list of their contents covering the years 18161850 will be found on page 378 of the "Autobiography".

Several years ago I wrote to the officer in command at Netley about this collection, and was informed that it had been transferred to Millbank. But last August, when through the kindness of Major-General Meneces I was allowed to examine the books which had come from Netley, I received a considerable shock on discovering that of the 128 volumes which constituted the collection as received at Millbank, only 25 belonged 
to the the period during which McGrigor was Director-General, and two others to that of Dr. Smith. The remainder dealt with various military medical reports covering the period 1858-1891. Most of the volumes still bear their original numbers and dates on their back strips, but in some instances the labels have been lost and the only method of determining their order was by examining the dates on which the various reports in them were written.

The volumes which originally belonged to McGrigor's vast collection are as follows:

Nos. 2 (1817), 35 (1819), 35 (1819), (Number missing) (1822-6), (ditto) (1824), 87 (1826), (ditto) (1826-31), 118 (1828-9), 131 (1829-30), 142 (1831), 154 (1833), 155 (1833), 157 (1833), 159 (1833), (ditto) (1835), (ditto) (1837-45), (ditto) (1838-9), (ditto) (1841), (ditto) (1841), (ditto) (1844), 285 (1848), 291 (1847-8), 292 (1847-8), 293 (1847-8), 294 (1848-9).

Those which date from Andrew Smith's term of office as Director-General are (Numbers missing) (1853-4), and (1848-1858), and also No. 395 (1857-8).

Since the reports contained in the foregoing volumes came from various British military stations, only a very few of them were concerned with the Cape of Good Hope. It was these in which I had hoped to find the reports which Andrew Smith wrote, as part of his regular duties, while he was stationed there from 1821 to 1836 . Fortunately I traced there two autograph reports written by Smith in 1826 and 1831, which explained how he could spend so much time on the study of Natural History. At Port Elizabeth, for example, where Smith was stationed throughout the year 1831, there was an average of only 29 men on the strength, and the total number of patients treated by him was 18 .

The discovery of these reports, and of the covering reports of the chief medical officer at the Cape, has confirmed my belief that a considerable amount of official information about Andrew Smith and his movements in South Africa, as well as of his contemporary colleagues, must be in the volumes that are missing from the collection. And the seven volumes entitled "Topography, with Maps", would, I am sure, be of inestimable value to students.

I now ask the question: where can the many missing volumes have got to? If any medical officer has come across any of them, or even heard of them, he would confer a great benefit upon Millbank if he would report the fact, and would earn the gratitude of historians who, like myself, are trying to fill in the gaps in a most fascinating story.

PERCIVAL R. KIRBY. 